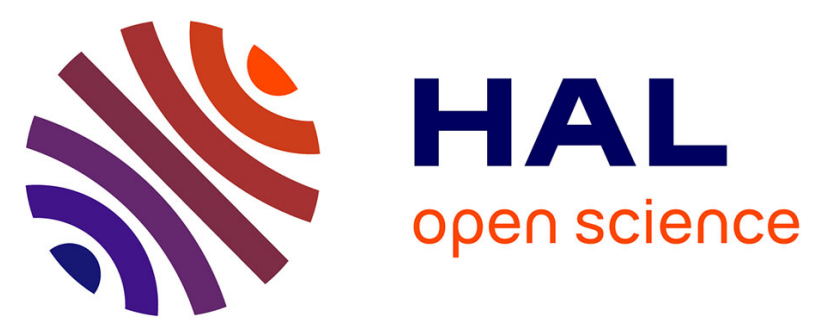

\title{
Patterns of care and the survival of elderly patients with high-risk endometrial cancer: A case-control study from the FRANCOGYN group
}

\author{
Aline Rousselin, Sofiane Bendifallah, Krystel Nyangoh Timoh, Lobna \\ Ouldamer, Geoffroy Canlorbe, Emilie Raimond, Nina Hudry, Charles \\ Coutant, Olivier Graesslin, Cyril Touboul, et al.
}

\section{To cite this version:}

Aline Rousselin, Sofiane Bendifallah, Krystel Nyangoh Timoh, Lobna Ouldamer, Geoffroy Canlorbe, et al.. Patterns of care and the survival of elderly patients with high-risk endometrial cancer: A case-control study from the FRANCOGYN group. EJSO - European Journal of Surgical Oncology, 2017, 43 (11), pp.2135-2142. 10.1016/j.ejso.2017.07.019 . hal-01661686

\section{HAL Id: hal-01661686}

\section{https://hal-univ-rennes1.archives-ouvertes.fr/hal-01661686}

Submitted on 12 Dec 2017

HAL is a multi-disciplinary open access archive for the deposit and dissemination of scientific research documents, whether they are published or not. The documents may come from teaching and research institutions in France or abroad, or from public or private research centers.
L'archive ouverte pluridisciplinaire HAL, est destinée au dépôt et à la diffusion de documents scientifiques de niveau recherche, publiés ou non, émanant des établissements d'enseignement et de recherche français ou étrangers, des laboratoires publics ou privés. 
Patterns of care and the survival of elderly patients with high-risk endometrial cancer: a casecontrol study from the FRANCOGYN group

Aline Rousselin ${ }^{1}$, Sofiane Bendifallah ${ }^{2,3}$, Krystel Nyangoh Timoh ${ }^{1}$, Lobna Ouldamer ${ }^{4}$, Geoffroy Canlorbe ${ }^{2}$, Emilie Raimond ${ }^{5}$, Nina Hudry ${ }^{6}$, Charles Coutant ${ }^{6}$, Olivier Graesslin ${ }^{5}$, Cyril Touboul ${ }^{7}$, Pierre Collinet $^{8}$, Alexandre Bricou ${ }^{9}$, Cyrille Huchon ${ }^{10}$, Emile Daraï ${ }^{2,11}$, Marcos Ballester ${ }^{2,11}$, Jean Levêque $^{1}$, Vincent Lavoue ${ }^{1}$

1. CHU de Rennes, Service de Gynécologie, Hopital Sud, 16 bd de Bulgarie, 35000 Rennes, FRANCE; Université de Rennes 1, France; ER440, Oncogenesis, Stress and Signaling, CRLCC Eugène Marquis, Rennes, France.

2. Department of Gynaecology and Obstetrics, Tenon University Hospital, Assistance Publique des Hôpitaux de Paris (AP-HP), University Pierre and Marie Curie, Paris 6, Institut Universitaire de Cancérologie (IUC), France.

3. INSERM UMR_S_707, "Epidemiology, Information Systems, Modeling", University Pierre and Marie Curie, Paris 6, France;

4. Department of Obstetrics and Gynaecology, Centre Hospitalier Régional Universitaire de Tours, Hôpital Bretonneau, Tours, France.

5. Department of Obstetrics and Gynaecology, Institute Alix de Champagne University Hospital, Reims, France.

6. Center de lutte contre le cancer Georges François Leclerc, Dijon, France.

7. Department of Obstetrics and Gynaecology, Centre Hospitalier Intercommunal, Créteil, France.

8. Department of Obstetrics and Gynaecology, Centre Hospitalier Régional Universitaire, Lille, France.

9. Department of Gynaecology and Obstetrics, Jean Verdier University Hospital, Assistance Publique 
des Hôpitaux de Paris (AP-HP), University Paris 13, France.

10. Department of Gynaecology and Obstetrics, Centre Hospitalier Intercommunal, Poissy, France,

11. INSERM UMR_S_938, University Pierre et Marie Curie, Paris 6, France

Corresponding author: Pr Vincent Lavoué. vincent.lavoue@chu-rennes.fr. Service de Gynécologie, CHU de Rennes, Hôpital Sud, 16 bd de Bulgarie 35000 Rennes, France. Tel.: + 33299264321.

The authors declare they have no conflicts of interest. 
Abstract

BACKGROUND: The standard of care of endometrial cancer involves complex procedures such as pelvic and para-aortic lymphadenectomy and omentectomy, particularly for high-risk endometrial cancer. Few data are available about these complex surgical procedures and adjuvant therapy in elderly women. We aim to examine treatment and survival of elderly women diagnosed with high-risk endometrial cancer.

STUDY DESIGN: We performed a case-control study of women diagnosed between 2001 and 2013 with high-risk endometrial cancers. Women older than 70 years $(n=198)$ were compared with patients $<70$ years $(n=198)$ after matching on high-risk for recurrence and LVSI status.

RESULTS: Elderly patients had lymphadenectomies less frequently compared with younger patients $(76 \%$ vs $96 \%, \mathrm{p}<0.001)$ and no adjuvant treatment more frequently $(17 \%$ vs $8 \%$, $\mathrm{p}=0.005)$ due to less chemotherapy being administered $(23 \%$ vs $46 \%, \mathrm{p}<0.001)$. The 3 -year DFS, CSS and OS of patients $\geq 70$ years was 52\% (43-61), 81\% (74-88) and 61\% (53-70), respectively. These were significantly lower than the 3-year DFS, CSS, and OS of younger patients, which was 75\% (68-82) $(\mathrm{p}<0.001), 92 \%(87-96)(\mathrm{p}<0.008)$ and $75 \%(69-82)$ $(p=0.018)$, respectively. Cox proportional hazard models found that elderly women had 57\% increased risk of recurrence (hazard ratio $1.57,95 \%$ CI 1.04-2.39) compared with younger patients. CONCLUSION: Although we found an independently significant lower DFS in elderly patients with high-risk endometrial cancer when compared with young patients, elderly women are less likely to be treated with lymphadenectomy and chemotherapy. Specific guidelines for management of elderly patients with high-risk endometrial cancer are required to improve their prognosis.

Key words: high-risk endometrial cancer; elderly; surgery; chemotherapy: cancer-specific survival 


\section{Introduction}

Endometrial cancer is the most common gynecologic malignancy in the western world, and in parallel to aging demographics, the incidence of endometrial cancer has also been increasing; the average age of diagnosis is approximately 68 years old (1-4). The standard of care for endometrial cancer remains controversial but mostly includes comprehensive surgical staging as recommended by the International Federation of Gynecology and Obstetrics (FIGO) (5). This standard of care can involve complex procedures such as pelvic and para-aortic lymphadenectomy and omentectomy, particularly for high-risk endometrial cancer (6-10). High-risk endometrial cancer, as defined by ESMO-ESGOESTRO guidelines (6), includes grade 3 adenocarcinoma with myometrial invasion of $>50 \%$, carcinosarcoma, uterine clear-cell carcinoma, and uterine serous carcinoma, accounts for a disproportionately high rate of cancer-specific mortality (11). More high-risk endometrial cancer and more advanced endometrial cancer was observed in elderly patients compared with their younger counterparts (12) and could explain the worse prognosis of endometrial cancer in elderly patients. The PORTEC III study and others evaluated adjuvant radiotherapy plus chemotherapy and showed higher survival rates for women who received adjuvant treatment (13-15). Despite the benefit of adjuvant therapy on survival for high-risk endometrial cancer, older patients receive an inferior level of care with poorer outcomes $(7,16,17)$. This substandard treatment secondary to advanced age alone could also be a major driver in decreased survival in the oldest individuals with endometrial cancer.

The objective of this study is to examine the patterns of care and survival for elderly with high-risk endometrial cancer while adjusting for variables traditionally identified as associated with poor prognosis. 


\section{Materials and methods}

- Patients

We conducted a case-control study from a retrospective data collection of patients with endometrial cancer who received primary surgical treatment between January 2001 and December 2013. The data were obtained from eight institutions in France who maintained endometrial cancer databases (Tours, Tenon, Dijon, Rennes, Lille, Reims, Creteil, Poissy, Jean Verdier Tertiary Hospitals) and from the Senti-Endo trial (18). The research protocol was approved by the Institutional Review Board of the College National des Gynécologues et Obstétriciens Français (CNGOF) in 2014.

The patients were divided into two cohorts: women $<70$ years old and women $\geq 70$ years old, designated young and elderly patients, respectively. In the elderly cohort, inclusion criteria were women with high-risk endometrial cancer (i.e. high-risk stage I EC and more advanced stage) on final histologic examination. High-risk endometrial cancer was defined using ESMO/ESTRO/ESGO criteria (19). Each elderly patient with high-risk endometrial cancer was matched with one control patient with high-risk endometrial cancer in the young cohort and matched on lymphovascular space involvement (LVSI) for stage I and endometrioid type I endometrial cancer $(20,21)$.

\section{- Data collection}

All patients had undergone a preoperative endometrial biopsy and underwent preoperative abdominopelvic magnetic resonance imaging (MRI) unless contraindicated. Demographic and clinical data were collected. We also collected the final pathological analysis: histological subtype, grade and stage based on the International Federation of Gynaecology and Obstetrics (FIGO) (2009) (22). Operative data surgical approach, nodal staging and adjuvant therapy were documented.

\section{- Histology}

Lymph nodes were considered positive when there were macro- and/or micrometastases. Macrometastases were defined as a single focus of metastatic disease per LN, measuring more than 2 $\mathrm{mm}$. Micrometastases were defined as a single focus of metastatic disease per LN, measuring between 0.2 and $2 \mathrm{~mm}$. A tumor is considered to have lymphovascular space involvement (LVSI) when tumor 
emboli are found within a space clearly lined by endothelial cells on a hematoxylin and eosin (H\&E)stained tumor tissue section (21).

Type 1 tumors consisted of endometrioid adenocarcinomas and mixed tumors with a mucinous, villoglandular or tubular component in addition to the endometrioid component. For these tumors, histological grade was defined by the percentage of the undifferentiated component: grade 3 corresponded to an undifferentiated component more than 50\% (23).

Type 2 tumors were those with at least one serous, clear cell or carcinosarcoma component.

All women were classified according to the FIGO 2009 classification (22) after final pathological analysis. The tumors were classified into recurrence risk groups as defined by the European Society for Medical Oncology (ESMO) / European Society of Gynaecological Oncology (ESGO) / European Society for Radiotherapy and Oncology (ESTRO) guidelines (19). High-risk endometrial cancer was defined by stage FIGO IB grade 3, and by extension, stage $\geq$ II histological type 1 as well as all type 2 tumors of any stage.

\section{- Treatment and follow-up}

Women underwent primary surgical treatment including at least total hysterectomy with bilateral salpingo-oophorectomy, with or without nodal staging (pelvic \pm paraaortic lymphadenectomy) according to the current guidelines (23) and the discretion of the surgeon. According to French guidelines, pelvic and para-aortic lymph node surgical staging is required for high-risk groups. Adjuvant therapy was administered on an individual basis at the discretion of a multidisciplinary committee based on the French guidelines and included vaginal brachytherapy (VBT) and/or external beam radiotherapy (EBRT) and/or chemotherapy (CT) and clinical follow-up (15). Clinical follow-up consisted of physical examinations and the use of imaging techniques according to the findings. Follow-up visits were conducted every 3 months for the first 2 years, every 6 months for the following 3 years, and once a year thereafter.

\section{- Recurrence events and outcome measures}


The main outcomes measures were the date of recurrence, date of death and date of cancer-related death. Disease recurrence was diagnosed by biopsy or imaging studies and defined as a relapse without differentiating between their local or distant nature. The secondary outcomes measures were surgical staging, in compliance with French national guidelines (23), and surgical route (minimally invasive surgery, laparotomy and vaginal surgery).

\section{- Statistical analysis}

Descriptive parameters were expressed as the mean ( \pm Standard Deviation $[\mathrm{SD}])$ and median [range] when indicated. Frequencies were presented as percentages. We compared the demographics and medical characteristics of patients in the two cohorts using Chi-square or Fisher's exact tests as appropriate. For continuous variables, we used t-tests. Overall survival time was calculated in months from the date of surgery to death (related or unrelated to cancer) or the date of last follow-up for the surviving patient. Cancer-specific survival (CSS) was calculated as the time from the date of surgery to cancer-related death, and disease-free survival (DFS) was calculated as time from the date of surgery to cancer recurrence. The Kaplan-Meier method was used to estimate the survival distribution. Survival was compared with log-rank test. Effects were expressed as hazard ratios (HRs) with 95\% confidence intervals as appropriate. Cox proportional hazard models included established prognostic factors: pathological type, adjuvant therapies, and nodal status. A p-value of $<0.05$ was considered statistically significant. Data were managed in an Excel database (Microsoft, Redmond, WA, USA) and analyzed using R 3.0.2 software, which is available online. 


\section{Results}

\section{- Characteristics of the study population}

During the study period, 1227 women with endometrial cancer were documented as having received primary surgical treatment. According to the two age groups, $747(61 \%)$ women were $<70$ years old, and $480(39 \%)$ were $\geq 70$ years old. From each group, 273/747 (36.5\%) and 220/480 (45.8\%) women were in the high-risk group ( $\mathrm{p}=0.001$ ). After matching on LVSI, there were 198 patients in each age group, i.e., 396 patients in the study population (figure 1).

The median age of the young patient cohort was 60 years (range 31-69 years), and their median BMI was $29.4 \mathrm{~kg} / \mathrm{m}^{2}$ (range 16.6-50.7). The median age of the elderly patient cohort was 77 years (range 70-98 years), and their median BMI was $27.4 \mathrm{~kg} / \mathrm{m}^{2}$ (range 14.0-41.3). The demographic and clinicopathological characteristics of the entire cohort by age group are reported in Table 1 . The rate of comorbidities, such as high blood pressure, was significantly higher in the elderly group $(\mathrm{p}<0.001)$.

\section{- $\quad$ Tumor characteristics}

The tumor characteristics are reported in Table 2. There were no significant differences between young and elderly patients concerning tumor size, myometrial invasion, histological type, grade, histological type, FIGO stage or known node involvement. Thus, as expected, known prognosis factors were similar in both groups.

\section{- Surgical characteristics and adjuvant treatment}

Surgical procedures are described in Table 3. Concerning the surgical approach, elderly women had significantly more hysterectomies with bilateral salpingo-oophorectomy by laparotomy $(91 / 198,46 \%)$, whereas young women had more laparoscopy surgeries $(107 / 198,54 \%)(\mathrm{p}=0.002)$. The rate of pelvic lymphadenectomy was $96 \%$ (190/198) and 76\% (150/198) for young and elderly patients, respectively ( $\mathrm{p}<0.001$ ). Notably, when pelvic lymphadenectomy was performed, the mean number of removed nodes was not significantly different. Young patients were more likely to undergo sentinel lymph node procedures compared to the elderly, with $34 \%(67 / 198)$ vs $20 \%(39 / 198),(\mathrm{p}=0.006)$, respectively. 
The adjuvant treatments are reported in table 3. No adjuvant treatment was performed in $16.8 \%$ $(33 / 198)$ of elderly and $8 \%(15 / 198)$ of young patients $(\mathrm{p}=0.005)$. Radiotherapy and vaginal brachytherapy was performed in $46.9 \%$ (93/198) of elderly and $34.4 \%(69 / 198)$ of young patients $(\mathrm{p}=0.014)$. Notably, 56 patients, 48 elderly and 8 young, had no pelvic lymphadenectomy. Among elderly patients with no pelvic lymphadenectomy, 40\% (19/48) had radiotherapy alone, and 58\% (28/48) had radiation and/or chemotherapy. Among young patients with no pelvic lymphadenectomy, $37.5 \%(3 / 8)$ had radiotherapy alone and $62.5 \%(5 / 8)$ had radiation and/or chemotherapy. Among elderly patients with pelvic lymphadenectomy (150 patients), 49\% (74/150) had radiotherapy alone, and $73 \%(110 / 150)$ had radiation and/or chemotherapy. Among young patients with pelvic lymphadenectomy, $34.7 \%(66 / 190)$ had radiotherapy alone, and $81.5 \%(115 / 190)$ had radiation and/or chemotherapy. In elderly patients, patients with no lymphadenectomy had adjuvant treatment (chemotherapy and/or radiotherapy) in only 58\% (28/48) of cases, while patients with lymphadenectomy had adjuvant treatment in $73 \%(110 / 150)$ of cases $(p=0.07)$.

\section{- Survival results}

The mean follow-up of the entire study population was $31.2( \pm 27.4)$ months. In the entire population, the 3-years DFS and OS were $64.1 \%(95 \% \mathrm{CI}, 58.6-70.2)$ and $68.9 \%$ (95\% CI, 63.6-74.6), respectively. In the overall population, recurrences were observed in 123 of the 396 women (31\%). The median and mean time of recurrence was 18.93 [0.1-154.2] and 27.63 ( \pm 26.98$)$ months, respectively. The survival curves are shown in figure 2 . The cancer-specific survival was significantly lower in the elderly $(\mathrm{p}=0.008)$ (figure $2 \mathrm{c}$ ). The three-year DFS, CSS and OS rates decreased significantly in the elderly in the univariate analysis (table S1), and the three-year DFS decreased significantly in the elderly in multivariate analysis (table 4). 


\section{Discussion}

In the present study, after matching patients with high-risk endometrial cancer for known prognostis factors, we found that DFS and CSS were significantly lower in elderly patients when compared with their younger counterparts. Moreover, we found that the elderly had significantly fewer lymphadenectomies and adjuvant treatments compared with younger counterparts. Finally, we found that lymphadenectomy was correlated with lower DFS, CSS and OS in multivariate analysis. This substandard treatment secondary to advanced age alone is a major driver in decreased survival among the oldest individuals with high-risk endometrial cancer.

The PORTEC 1 trial showed that women over the age of 60 were threefold more likely to have a locoregional recurrence following radical surgery compared to younger patients (HR $3.90 \mathrm{p}=0.0017$ ) (13). No data that deal with only high-risk EC and age exist in literature (except Rauh-hain study (33), but mix high-risk EC and advanced stage EC). Elderly patients with endometrial cancer had lower rates of surgical staging, often with lymphadenectomy omitted $(1,16,24)$. The role of lymphadenectomy still represents a subject of passionate debates within the scientific community (2528). Todo Y. et al. demonstrated that the combination of pelvic and para-aortic lymphadenectomy can significantly improve survival in patients with high-risk endometrial cancer (29). Although only highrisk endometrial cancer was included, the present study showed a low rate of para-aortic lymphadenectomy, particularly in the in elderly ( $35 \%$ vs $11 \%)$. This low rate could be due to the data collection period and changes in staging modalities (FIGO classification) and in the indications for nodal staging and adjuvant therapies that occurred during the data collection period. The lower rate of lymph node dissection in the elderly patients could have been due to a discrepancy between pre- and postoperative risk group assessment. Lastly, there was a primary difference in the Todo patient population. In the Todo $\mathrm{Y}$ et al. study, overall patients were younger with mean age of $56.2( \pm 9.2)$ years compared to a young patient cohort mean age of $59.6( \pm 6.8)$ years and an elderly cohort mean age of $76.9( \pm 5.3)$ years in the present study. This fact indicates that elderly patients were not included in the Todo Y et al. study (29). Although sentinel lymph node biopsy is less used in the elderly in the present study, this technical detail could lead to optimal lymph node evaluation without pelvic and 
para-aortic lymphadenectomy, and thus could be very useful in high-risk endometrial cancer, especially in elderly $(18,30)$.

Minimally invasive surgery is offered less in older patients, and this is likely due to the reluctance to performe minimally invasive surgery on the elderly due to possible contraindications to laparoscopy (31). Nevertheless, recent data demonstrated that minimally invasive surgical treatment of endometrial cancer, robotically assisted or not, is feasible and safe in elderly patients and is superior to open surgery in terms of peri-operative procedure results, independent of age $(12,32)$.

In the present study, the elderly were significantly less likely to receive chemotherapy compared with young patients (33). Similar to surgery, balancing benefits against the risks of adjuvant endometrial cancer treatment in older patient populations is challenging. Although medical comorbidities may preclude its use in some patients, the cause for the lower rate of chemotherapy utilization in older patients is unclear. The decision of whether or not to perform chemotherapy is not based on rational and reproduced evaluation criteria in the present study (34).

As opposed to a study by Rauh-hain (33), the present work found a higher rate of radiotherapy in elderly patients. This point was in accordance with the breadth of literature reporting that radiotherapy increases survival and is generally well tolerated in elderly patients $(13,35)$.

Some limitations in the present analysis must be considered when interpreting the data. A common concern with observational data is the potential for selection bias, in which unobserved dimensions of health status, such as performance status, may determine treatment and independently affect survival, as we described above. Indeed, the number of comorbidities was significantly higher in elderly patients. Similarly, elderly patients with no lymphadenectomy received adjuvant treatment less often when compared with elderly patients with lymphadenectomy $(\mathrm{p}=0.07)$, leading to the conclusion that at least subjectively evaluated health status is likely considered by the physician when determining patient care. The high burden of medical comorbidities, financial and geographic barriers to care, and patient preferences may influence treatment and survival (36). Nevertheless, similar to other studies, no objective evaluation was used to tailor surgical staging or adjuvant treatment. Additionally, no attempt was made to replace numerical age by criteria evaluating life expectancy; most studies define 
the cutoff for elderly women at the age of 70 (37-43). One of the strengths of our investigations is that a notable number patients included had high-risk endometrial cancer, paired by prognosis factors in both elderly and young cohorts. Finally, the primary strength of this study is the use of cancer-specific mortality as opposed to all-cause mortality.

\section{Conclusion}

Elderly women with endometrial cancer often had the most aggressive histologic types and yet were treated with less lymphadenectomy and less chemotherapy than their younger counterparts. This finding may partly explain the increase in mortality from endometrial cancer with increasing age. These findings support the development of abbreviated geriatric assessments to risk stratify older patients into those who are likely to suffer from excess toxicity and those who are not. Specific guidelines to manage elderly and very elderly patients with endometrial cancer are needed to improve their prognosis. 


\section{References}

1. Edwards BK, Howe HL, Ries LAG, Thun MJ, Rosenberg HM, Yancik R, et al. Annual report to the nation on the status of cancer, 1973-1999, featuring implications of age and aging on U.S. cancer burden. Cancer. 2002 May 15;94(10):2766-92.

2. Siegel R, Ward E, Brawley O, Jemal A. Cancer statistics, 2011: the impact of eliminating socioeconomic and racial disparities on premature cancer deaths. CA Cancer J Clin. 2011 Aug;61(4):212-36.

3. Yancik R, Ries LAG. Cancer in older persons: an international issue in an aging world. Semin Oncol. 2004 Apr;31(2):128-36.

4. Siegel RL, Miller KD, Jemal A. Cancer statistics, 2016. CA Cancer J Clin. 2016 Feb;66(1):7-30.

5. Mikuta JJ. International Federation of Gynecology and Obstetrics staging of endometrial cancer 1988. Cancer. 1993 Feb 15;71(4 Suppl):1460-3.

6. Colombo N, Preti E, Landoni F, Carinelli S, Colombo A, Marini C, et al. Endometrial cancer: ESMO Clinical Practice Guidelines for diagnosis, treatment and follow-up. Ann Oncol. 2013 Oct 1;24(suppl 6):vi33-vi38.

7. Zeng XZ, Lavoue V, Lau S, Press JZ, Abitbol J, Gotlieb R, et al. Outcome of robotic surgery for endometrial cancer as a function of patient age. Int J Gynecol Cancer Off J Int Gynecol Cancer Soc. 2015 May;25(4):637-44.

8. Bendifallah $S$, Canlorbe $G$, Collinet $P$, Arsène $E$, Huguet $F$, Coutant $C$, et al. Just how accurate are the major risk stratification systems for early-stage endometrial cancer? Br J Cancer. $2015 \mathrm{Mar}$ 3;112(5):793-801.

9. SGO Clinical Practice Endometrial Cancer Working Group, Burke WM, Orr J, Leitao M, Salom E, Gehrig P, et al. Endometrial cancer: a review and current management strategies: part I. Gynecol Oncol. 2014 Aug;134(2):385-92.

10. SGO Clinical Practice Endometrial Cancer Working Group, Burke WM, Orr J, Leitao M, Salom E, Gehrig P, et al. Endometrial cancer: a review and current management strategies: part II. Gynecol Oncol. 2014 Aug;134(2):393-402.

11. Lachance JA, Everett EN, Greer B, Mandel L, Swisher E, Tamimi H, et al. The effect of age on clinical/pathologic features, surgical morbidity, and outcome in patients with endometrial cancer. Gynecol Oncol. 2006 Jun;101(3):470-5.

12. Lavoue V, Zeng X, Lau S, Press JZ, Abitbol J, Gotlieb R, et al. Impact of robotics on the outcome of elderly patients with endometrial cancer. Gynecol Oncol. 2014 Jun;133(3):556-62.

13. de Boer SM, Powell ME, Mileshkin L, Katsaros D, Bessette P, Haie-Meder C, et al. Toxicity and quality of life after adjuvant chemoradiotherapy versus radiotherapy alone for women with high-risk endometrial cancer (PORTEC-3): an open-label, multicentre, randomised, phase 3 trial. Lancet Oncol. 2016 Aug;17(8):1114-26.

14. Randall ME, Filiaci VL, Muss H, Spirtos NM, Mannel RS, Fowler J, et al. Randomized phase III trial of whole-abdominal irradiation versus doxorubicin and cisplatin chemotherapy in advanced 
endometrial carcinoma: a Gynecologic Oncology Group Study. J Clin Oncol Off J Am Soc Clin Oncol. 2006 Jan 1;24(1):36-44.

15. Hogberg T, Signorelli M, de Oliveira CF, Fossati R, Lissoni AA, Sorbe B, et al. Sequential adjuvant chemotherapy and radiotherapy in endometrial cancer--results from two randomised studies. Eur J Cancer Oxf Engl 1990. 2010 Sep;46(13):2422-31.

16. Wright JD, Lewin SN, Barrena Medel NI, Sun X, Burke WM, Deutsch I, et al. Endometrial cancer in the oldest old: Tumor characteristics, patterns of care, and outcome. Gynecol Oncol. 2011 Jul;122(1):69-74.

17. AlHilli MM, Bakkum-Gamez JN, Mariani A, Weaver AL, McGree ME, Keeney GL, et al. Riskadjusted outcomes in elderly endometrial cancer patients: implications of the contrasting impact of age on progression-free and cause-specific survival. Gynecol Oncol. 2015 Jul;138(1):133-40.

18. Ballester M, Dubernard G, Lécuru F, Heitz D, Mathevet P, Marret H, et al. Detection rate and diagnostic accuracy of sentinel-node biopsy in early stage endometrial cancer: a prospective multicentre study (SENTI-ENDO). Lancet Oncol. 2011 May;12(5):469-76.

19. Colombo N, Creutzberg C, Amant F, Bosse T, González-Martín A, Ledermann J, et al. ESMOESGO-ESTRO Consensus Conference on Endometrial Cancer: Diagnosis, Treatment and Followup. Int J Gynecol Cancer Off J Int Gynecol Cancer Soc. 2016 Jan;26(1):2-30.

20. Bendifallah S, Canlorbe G, Raimond E, Hudry D, Coutant C, Graesslin O, et al. External validation of nomograms designed to predict lymphatic dissemination in patients with early-stage endometrioid endometrial cancer: a multicenter study. Am J Obstet Gynecol. 2015 Jan;212(1):56.e1-7.

21. Briët JM, Hollema H, Reesink N, Aalders JG, Mourits MJE, ten Hoor KA, et al. Lymphvascular space involvement: an independent prognostic factor in endometrial cancer. Gynecol Oncol. 2005 Mar;96(3):799-804.

22. Pecorelli S. Revised FIGO staging for carcinoma of the vulva, cervix, and endometrium. Int J Gynaecol Obstet Off Organ Int Fed Gynaecol Obstet. 2009 May;105(2):103-4.

23. Querleu D, Planchamp F, Narducci F, Morice P, Joly F, Genestie C, et al. Clinical practice guidelines for the management of patients with endometrial cancer in France: recommendations of the Institut National du Cancer and the Société Française d'Oncologie Gynécologique. Int J Gynecol Cancer Off J Int Gynecol Cancer Soc. 2011 Jul;21(5):945-50.

24. Bourgin C, Saidani M, Poupon C, Cauchois A, Foucher F, Leveque J, et al. Endometrial cancer in elderly women: Which disease, which surgical management? A systematic review of the literature. Eur J Surg Oncol J Eur Soc Surg Oncol Br Assoc Surg Oncol. 2016 Feb;42(2):166-75.

25. Uccella S, Podratz KC, Aletti GD, Mariani A. Lymphadenectomy in endometrial cancer. Lancet Lond Engl. 2009 Apr 4;373(9670):1170; author reply 1170-1171.

26. Cormier B, Rozenholc AT, Gotlieb W, Plante M, Giede C, Communities of Practice (CoP) Group of Society of Gynecologic Oncology of Canada (GOC). Sentinel lymph node procedure in endometrial cancer: A systematic review and proposal for standardization of future research. Gynecol Oncol. 2015 Aug;138(2):478-85. 
27. ASTEC study group, Kitchener $\mathrm{H}$, Swart AMC, Qian $\mathrm{Q}$, Amos $\mathrm{C}$, Parmar MKB. Efficacy of systematic pelvic lymphadenectomy in endometrial cancer (MRC ASTEC trial): a randomised study. Lancet Lond Engl. 2009 Jan 10;373(9658):125-36.

28. Benedetti Panici P, Basile S, Maneschi F, Alberto Lissoni A, Signorelli M, Scambia G, et al. Systematic pelvic lymphadenectomy vs. no lymphadenectomy in early-stage endometrial carcinoma: randomized clinical trial. J Natl Cancer Inst. 2008 Dec 3;100(23):1707-16.

29. Todo Y, Kato H, Kaneuchi M, Watari H, Takeda M, Sakuragi N. Survival effect of para-aortic lymphadenectomy in endometrial cancer (SEPAL study): a retrospective cohort analysis. Lancet Lond Engl. 2010 Apr 3;375(9721):1165-72.

30. Ghezzi F, Casarin J, Uccella S. Mini-laparoscopic Sentinel Node Detection in Endometrial Cancer: Further Reducing Invasiveness for Patients with Early-Stage Disease. Ann Surg Oncol. 2015 Dec;22 Suppl 3:S342.

31. Ball A, Bentley JR, O'Connell C, Kieser KE. Choosing the right patient: planning for laparotomy or laparoscopy in the patient with endometrial cancer. J Obstet Gynaecol Can JOGC J Obstet Gynecol Can JOGC. 2011 May;33(5):468-74.

32. Uccella S, Bonzini M, Palomba S, Fanfani F, Malzoni M, Ceccaroni M, et al. Laparoscopic vs. open treatment of endometrial cancer in the elderly and very elderly: An age-stratified multicenter study on 1606 women. Gynecol Oncol. 2016 May;141(2):211-7.

33. Rauh-Hain JA, Pepin KJ, Meyer LA, Clemmer JT, Lu KH, Rice LW, et al. Management for Elderly Women With Advanced-Stage, High-Grade Endometrial Cancer. Obstet Gynecol. 2015 Dec;126(6):1198-206.

34. Dumas L, Ring A, Butler J, Kalsi T, Harari D, Banerjee S. Improving outcomes for older women with gynaecological malignancies. Cancer Treat Rev. 2016 Aug 29;50:99-108.

35. Wegner RE, Beriwal S, Heron DE, Richard SD, Kelly JL, Edwards RP, et al. Definitive radiation therapy for endometrial cancer in medically inoperable elderly patients. Brachytherapy. 2010 Sep;9(3):260-5.

36. Prince MJ, Wu F, Guo Y, Gutierrez Robledo LM, O'Donnell M, Sullivan R, et al. The burden of disease in older people and implications for health policy and practice. Lancet Lond Engl. 2015 Feb 7;385(9967):549-62.

37. Oresanya LB, Lyons WL, Finlayson E. Preoperative assessment of the older patient: a narrative review. JAMA. 2014 May;311(20):2110-20.

38. Story DA, Leslie K, Myles PS, Fink M, Poustie SJ, Forbes A, et al. Complications and mortality in older surgical patients in Australia and New Zealand (the REASON study): a multicentre, prospective, observational study. Anaesthesia. 2010 Oct;65(10):1022-30.

39. Susini T, Massi G, Amunni G, Carriero C, Marchionni M, Taddei G, et al. Vaginal hysterectomy and abdominal hysterectomy for treatment of endometrial cancer in the elderly. Gynecol Oncol. 2005 Feb;96(2):362-7.

40. Vaknin Z, Perri T, Lau S, Deland C, Drummond N, Rosberger Z, et al. Outcome and quality of life in a prospective cohort of the first 100 robotic surgeries for endometrial cancer, with focus on elderly patients. Int J Gynecol Cancer Off J Int Gynecol Cancer Soc. 2010 Nov;20(8):1367-73. 
41. Uyar D, Frasure HE, Markman M, von Gruenigen VE. Treatment patterns by decade of life in elderly women (> or $=70$ years of age) with ovarian cancer. Gynecol Oncol. 2005 Sep;98(3):4038.

42. Sundararajan V, Hershman D, Grann VR, Jacobson JS, Neugut Al. Variations in the use of chemotherapy for elderly patients with advanced ovarian cancer: a population-based study. J Clin Oncol Off J Am Soc Clin Oncol. 2002 Jan 1;20(1):173-8.

43. Rogers CG, Sammon JD, Sukumar S, Diaz M, Peabody J, Menon M. Robot assisted radical prostatectomy for elderly patients with high risk prostate cancer. Urol Oncol. 2013 Feb;31(2):193-7. 
Table 1: Patient characteristics

\begin{tabular}{|c|c|c|c|}
\hline Characteristics & $\begin{array}{c}\text { Age }<70 \text { years } \\
\text { n }(\%) \\
\mathbf{N}=198\end{array}$ & $\begin{array}{c}\text { Age } \geq 70 \text { years } \\
\mathbf{n}(\%) \\
\mathbf{N}=198\end{array}$ & $P$ value \\
\hline Age (years), mean ( $(\mathrm{SD})$ & $59.6( \pm 6.8)$ & $76.9( \pm 5.3)$ & $<0.001$ \\
\hline BMI $(\mathrm{kg} / \mathrm{m} 2)$, mean $( \pm \mathrm{SD})$ & $29.4( \pm 8.1)$ & $27.4( \pm 5.8)$ & $0.007^{-}$ \\
\hline \multicolumn{4}{|l|}{ Parity } \\
\hline-0 & $25(13 \%)$ & $16(8 \%)$ & 0.300 \\
\hline-1 & $37(19 \%)$ & $30(15 \%)$ & \\
\hline$-\geq 2$ & $91(46 \%)$ & $101(51 \%)$ & \\
\hline$-\mathrm{NC}$ & $45(22 \%)$ & $51(26 \%)$ & \\
\hline \multicolumn{4}{|l|}{ Menopause } \\
\hline - Yes & $166(84 \%)$ & $198(100 \%)$ & $<0.001$ \\
\hline No & $19(10 \%)$ & 0 & \\
\hline $\mathrm{NC}$ & $13(6 \%)$ & 0 & \\
\hline \multicolumn{4}{|l|}{ Arterial hypertension } \\
\hline -Yes & $58(29 \%)$ & $93(47 \%)$ & $<0.001$ \\
\hline$-\mathrm{No}$ & $105(53 \%)$ & $66(33 \%)$ & \\
\hline$-\mathrm{NC}$ & $35(18 \%)$ & $39(20 \%)$ & \\
\hline \multicolumn{4}{|l|}{ Diabetes } \\
\hline Yes & $26(13 \%)$ & $34(17 \%)$ & 0.500 \\
\hline$-\mathrm{No}$ & $151(76 \%)$ & $146(74 \%)$ & \\
\hline$-\mathrm{NC}$ & $21(11 \%)$ & $18(9 \%)$ & \\
\hline \multicolumn{4}{|l|}{ Menopausal hormone therapy } \\
\hline- Yes & $27(14 \%)$ & $29(15 \%)$ & 0.240 \\
\hline No & $113(57 \%)$ & $97(49 \%)$ & \\
\hline$-\mathrm{NC}$ & $58(29 \%)$ & $72(36 \%)$ & \\
\hline \multicolumn{4}{|l|}{ Breast cancer antecedent } \\
\hline$-\mathrm{Yes}$ & $14(7 \%)$ & $21(11 \%)$ & 0.420 \\
\hline No & $122(62 \%)$ & $121(61 \%)$ & \\
\hline $\mathrm{NC}$ & $62(31 \%)$ & $56(28 \%)$ & \\
\hline \multicolumn{4}{|l|}{ Comorbidity } \\
\hline 0 & $73(37 \%)$ & $41(21 \%)$ & $<0.001$ \\
\hline 1. & $50(25 \%)$ & $86(43 \%)$ & \\
\hline$\geq 2$ & $23(12 \%)$ & $31(16 \%)$ & \\
\hline $\mathrm{NC}$ & $52(26 \%)$ & $40(20 \%)$ & \\
\hline
\end{tabular}

BMI: body mass index; NC: not communicated; and SD: standard deviation 
Table 2: Tumor characteristics

\begin{tabular}{|c|c|c|c|}
\hline Charactéristics & $\begin{array}{c}\text { Age }<70 \text { years } \\
\mathbf{n}(\%) \\
\mathbf{N}=198\end{array}$ & $\begin{array}{c}\text { Age } \geq 70 \text { years } \\
\mathbf{n}(\%) \\
\mathbf{N}=198\end{array}$ & $\begin{array}{c}P \\
\text { value }\end{array}$ \\
\hline \multicolumn{4}{|l|}{ Tumour size } \\
\hline$-<3.5 \mathrm{~cm}$ & $49(25 \%)$ & $33(17 \%)$ & 0.090 \\
\hline$-\geq 3.5 \mathrm{~cm}$ & $87(44 \%)$ & $88(44 \%)$ & \\
\hline$-\mathrm{NC}$ & $62(31 \%)$ & $77(39 \%)$ & \\
\hline \multicolumn{4}{|l|}{ Myometrial invasion } \\
\hline$-<50 \%$ & $60(30 \%)$ & $47(24 \%)$ & 0.069 \\
\hline$-\geq 50 \%$ & $113(57 \%)$ & $135(68 \%)$ & \\
\hline$-\mathrm{NC}$ & $25(13 \%)$ & $16(8 \%)$ & \\
\hline \multicolumn{4}{|l|}{ Histology } \\
\hline - Endometrioid & $109(55 \%)$ & $97(49 \%)$ & 0.530 \\
\hline - Serous & $30(15 \%)$ & $35(17 \%)$ & \\
\hline - Clear cells & $25(13 \%)$ & $24(12 \%)$ & \\
\hline - Other * & $33(17 \%)$ & $42(22 \%)$ & \\
\hline$-\mathrm{NC}$ & 1 & 0 & \\
\hline \multicolumn{4}{|l|}{ Histological type } \\
\hline - Type 1 & $119(60 \%)$ & $106(54 \%)$ & 0.170 \\
\hline - Type 2 & $79(40 \%)$ & $92(46 \%)$ & \\
\hline$-\mathrm{NC}$ & 0 & 0 & \\
\hline \multicolumn{4}{|l|}{ Histological grade } \\
\hline-1 & $31(16 \%)$ & $28(14 \%)$ & 0.785 \\
\hline-2 & $45(23 \%)$ & $43(22 \%)$ & \\
\hline-3 & $118(60 \%)$ & $125(63 \%)$ & \\
\hline$-\mathrm{NC}$ & $4(1 \%)$ & $2(1 \%)$ & \\
\hline \multicolumn{4}{|c|}{ Lymphovascular space involvement } \\
\hline- Yes & $118(60 \%)$ & $118(60 \%)$ & 1 \\
\hline$-\mathrm{No}$ & $80(40 \%)$ & $80(40 \%)$ & \\
\hline$\therefore \mathrm{NC}$ & 0 & 0 & \\
\hline \multicolumn{4}{|l|}{ Pelvic lymph node metastasis } \\
\hline Y Yes & $43(22 \%)$ & $33(17 \%)$ & 0.889 \\
\hline - No & $147(74 \%)$ & $117(59 \%)$ & \\
\hline$-\mathrm{NC}$ & $8(4 \%)$ & $48(24 \%)$ & \\
\hline \multicolumn{4}{|c|}{ Para-aortic lymph node metastasis } \\
\hline- Yes & $17(9 \%)$ & $7(4 \%)$ & 0.581 \\
\hline - No & $52(26 \%)$ & $15(8 \%)$ & \\
\hline$-\mathrm{NC}$ & $129(65 \%)$ & $176(88 \%)$ & \\
\hline \multicolumn{4}{|l|}{ FIGO stage } \\
\hline 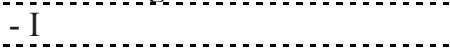 & $61(31 \%)$ & $67(34 \%)$ & 0.519 \\
\hline - II-III & $137(69 \%)$ & $131(66 \%)$ & \\
\hline$-\mathrm{IV}$ & 0 & 0 & \\
\hline
\end{tabular}

* mucinous, carcinosarcoma or undifferentiated

NC: not communicated 
Table 3: Surgical characteristics and adjuvant treatment

\begin{tabular}{|c|c|c|c|}
\hline Charactéristics & $\begin{array}{c}\text { Age }<70 \text { years } \\
\text { n }(\%) \\
N=198\end{array}$ & $\begin{array}{c}\text { Age } \geq 70 \text { years } \\
\mathbf{n}(\%) \\
N=198\end{array}$ & $\begin{array}{c}P \\
\text { value }\end{array}$ \\
\hline \multicolumn{4}{|l|}{ Surgical approach: } \\
\hline - Laparoscopy & $107(54 \%)$ & $79(40 \%)$ & 0.002 \\
\hline - Laparotomy & $72(36 \%)$ & $91(46 \%)$ & \\
\hline - Vaginal approach & 1 & $11(6 \%)$ & \\
\hline$-\mathrm{NC}$ & $18(9 \%)$ & $17(8 \%)$ & \\
\hline \multicolumn{4}{|l|}{ Sentinel lymph node } \\
\hline- Yes & $67(34 \%)$ & $39(20 \%)$ & 0.006 \\
\hline$-\mathrm{No}$ & $97(49 \%)$ & $117(59 \%)$ & \\
\hline$\therefore \mathrm{NC}$ & $34(17 \%)$ & $42(21 \%)$ & \\
\hline \multicolumn{4}{|l|}{ Pelvic lymphadenectomy } \\
\hline Y Yes & $190(96 \%)$ & $150(76 \%)$ & $<0.001$ \\
\hline$-\mathrm{No}$ & $8(4 \%)$ & $48(24 \%)$ & \\
\hline \multicolumn{4}{|l|}{ Para-aortic lymphadenectomy } \\
\hline Y Yes & $69(35 \%)$ & $21(11 \%)$ & $<0.001$ \\
\hline No & $129(65 \%)$ & $177(89 \%)$ & \\
\hline Nb. pelvic node, mean ( \pm SD $)$ & $13.0( \pm 6.8)$ & $11.0( \pm 6.9)$ & 0.068 \\
\hline Nb. para-aortic node, mean $( \pm \mathrm{SD})$ & $13.6( \pm 8.9)$ & $11.3( \pm 8.4)$ & 0.275 \\
\hline No adjuvant treatment & $15(8 \%)$ & $33(16.8 \%)$ & 0.005 \\
\hline $\begin{array}{l}\text { External beam radiotherapy and } \\
\text { other }\end{array}$ & $69(34.4 \%)$ & $93(46.9 \%)$ & 0.014 \\
\hline Chemotherapy and other & $91(46 \%)$ & $45(22.7 \%)$ & $<0.001$ \\
\hline Vaginal brachytherapy & $23(11.6 \%)$ & $27(13.6 \%)$ & $0.545^{-}$ \\
\hline
\end{tabular}

NC: Not communicated; SD: Standard Deviation 


\section{ACCEPTED MANUSCRIPT}

Table 4: Three-year disease-free survival, cancer-specific survival and overall survival rates (multivariate analysis)

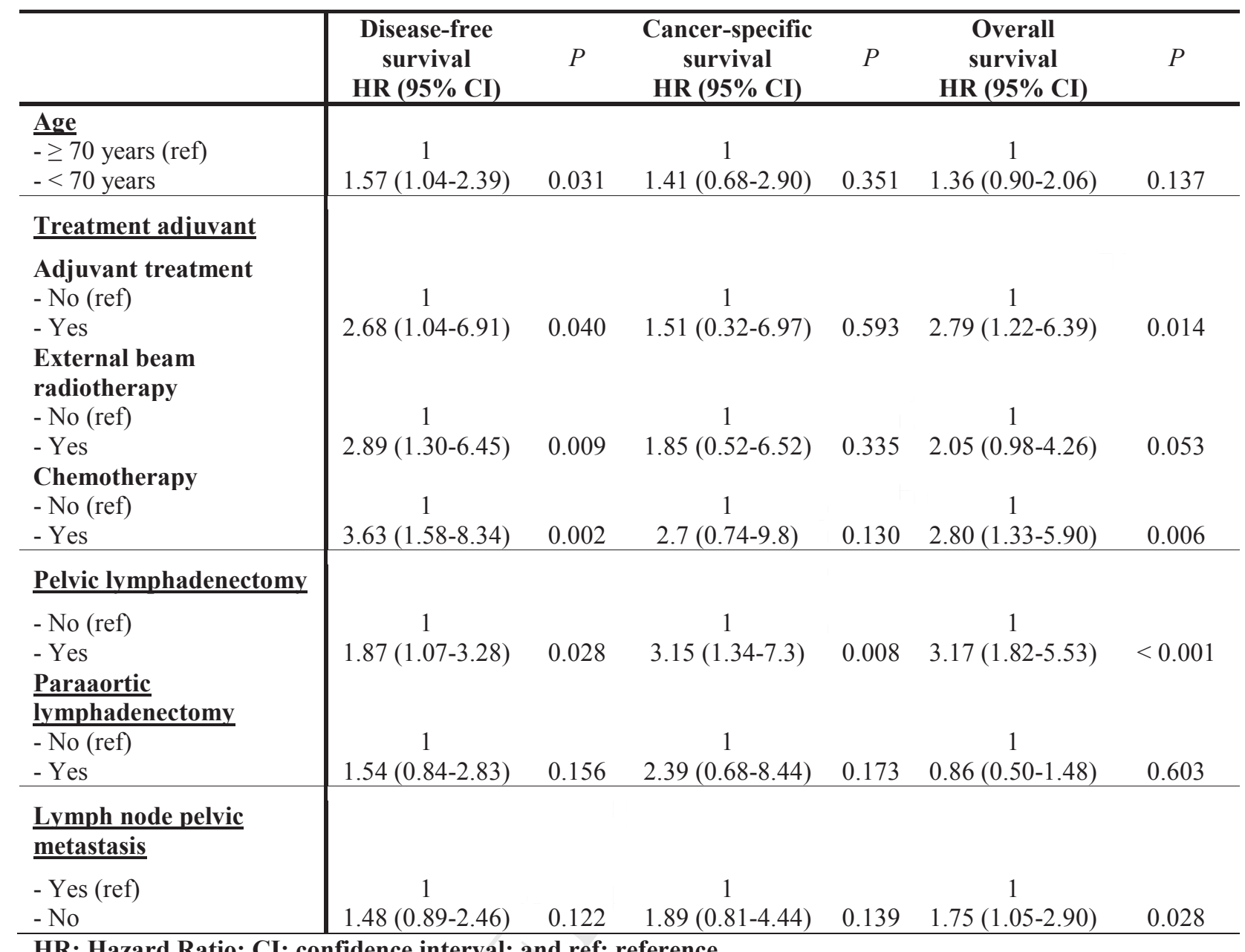

HR: Hazard Ratio; CI: confidence interval; and ref: reference 
Figure 1: Flow chart

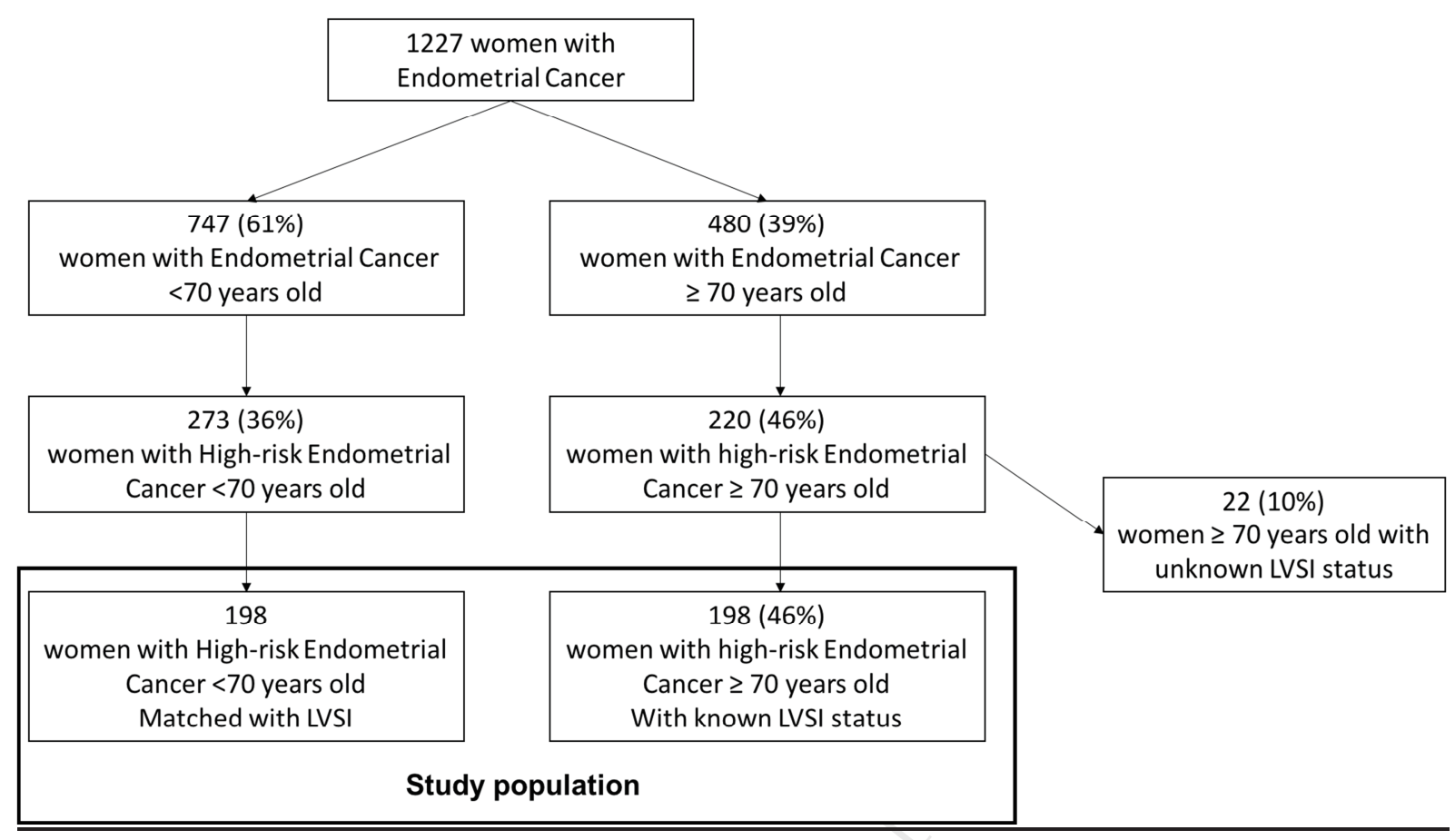


Figure 2: Kaplan-Meier overall survival (A), recurrence free survival (B), and cancer-specific survival (C) curves

A

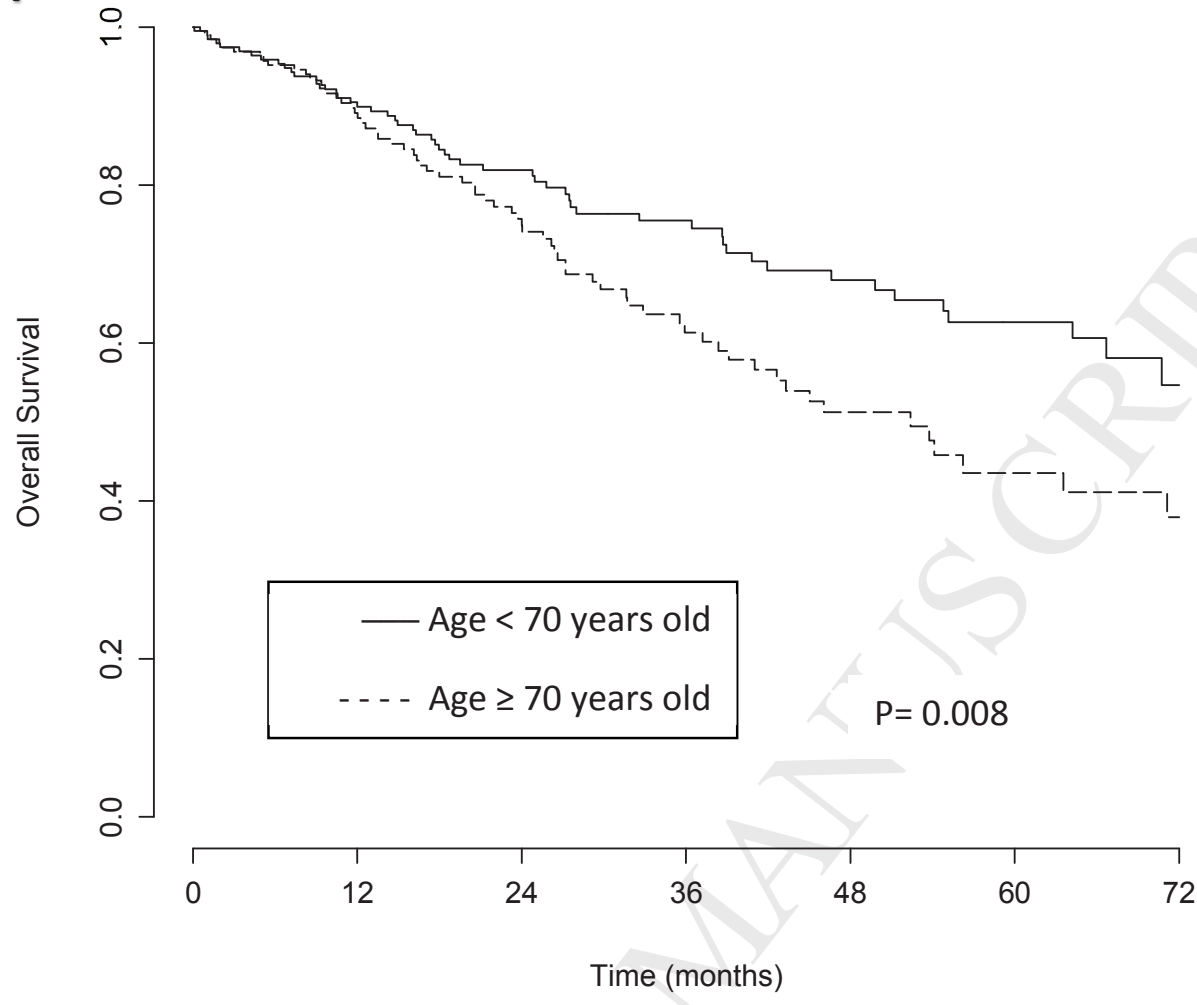

B

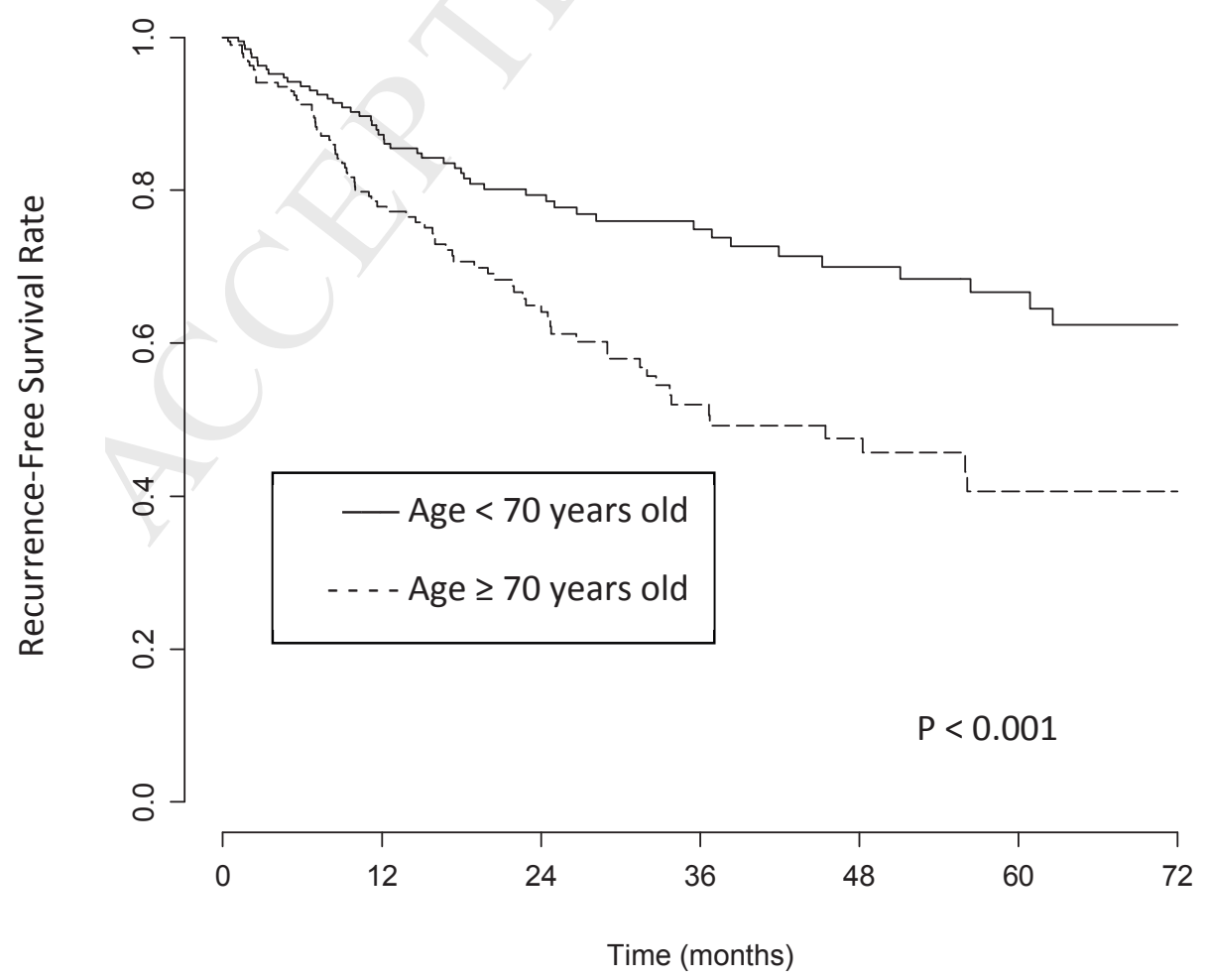


C

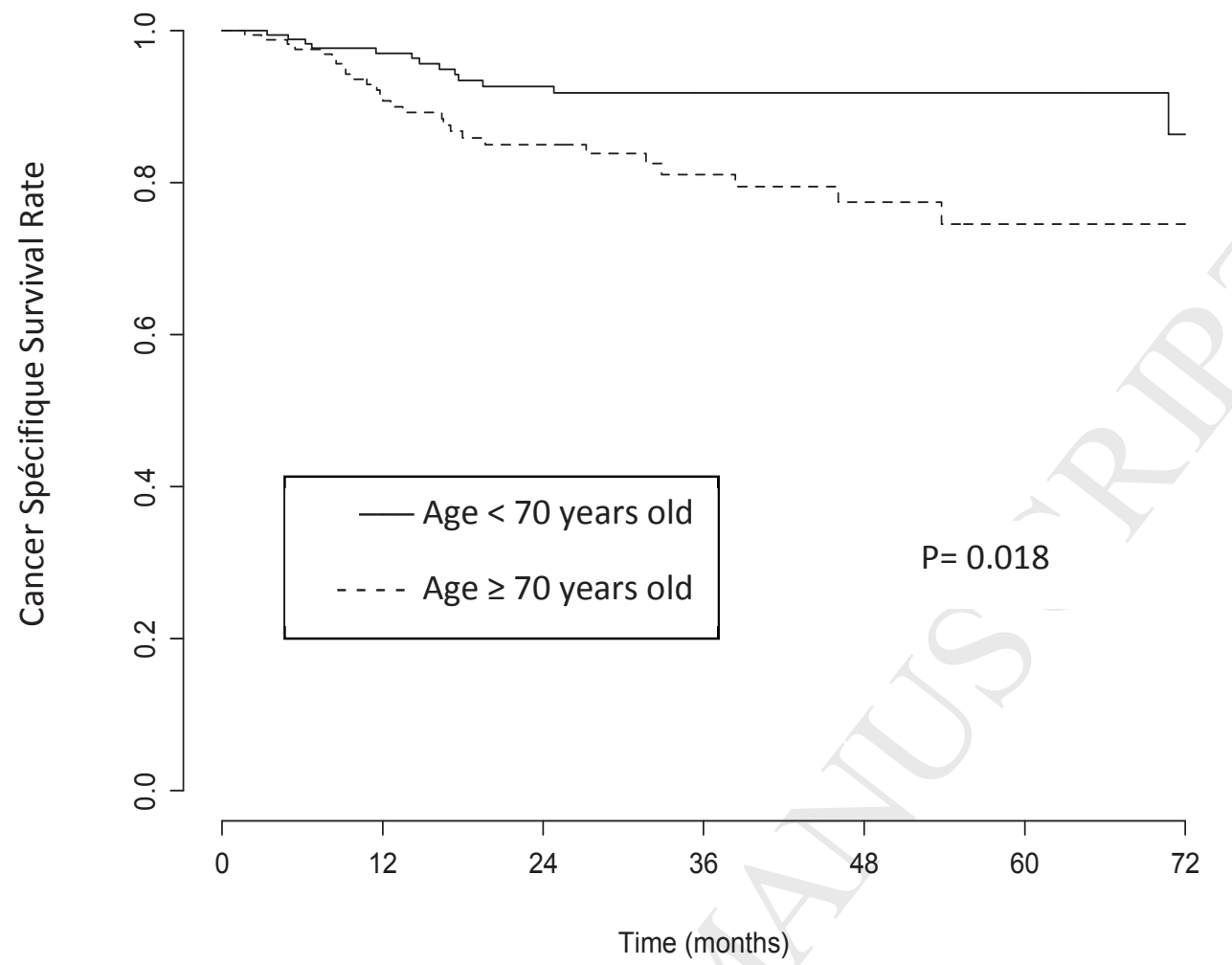

